\title{
Pediatric Psoriasis: Clinical Features and Course
}

\author{
Elvina Murzina* \\ Department of Dermatovenereology, Shupyk National Medical Academy of Postgraduate Education, Ukraine
}

\begin{abstract}
Psoriasis is fairly common dermatosis among children and adolescents, equally striking males and females. The article provides insight into clinical features and epidemiology of pediatric psoriasis in children aged 4-17. The disease was found to set in at any age, typically at the age of 9-10 years and have chronic course with durable exacerbation periods, lasting from few weeks up to 1-1.5 years. The highest number of psoriasis exacerbations takes place in autumn and winter months. Among the psoriasis triggers in children, stressful situations head the list. In children with psoriasis the extensive process prevails, plaque psoriasis is more likely to occur. The number of children with a localized type (scalp lesions) increases with age, whereas the manifestations of guttate and inverse psoriasis decrease in number.

KEYWORDS: Pediatric psoriasis; Epidemiology of psoriasis; Clinical features; Psoriasis types, plaque psoriasis; Guttate psoriasis; Children
\end{abstract}

\section{INTRODUCTION}

The prevalence of psoriasis within different populations ranges between 1 and $11.8 \%$. The highest rates among European countries were reported in Denmark (2.9\%) and the Faroe Islands (2.8\%) comparing to the average prevalence of psoriasis in Northern Europe of about 2\%. In the United States these figures range between 2.2 and $2.6 \%$, while almost 150,000 new cases are annually reported. Both males and females are equally predisposed to psoriasis [1-3].

Psoriasis can set in at any age. Approximately $14.8 \%$ to one third of all psoriasis cases occur by the age of 15 . The prevalence of the disease increases linearly: from $0.2 \%$ among 1 -year-olds to $1.2 \%$ among 18-year-olds, but the occurrence in children under the age of 10 is still nontypical. The most likely period for disease development is the age between 15 and 30 years. Currently, data was released revealing the 2 -fold rise in the incidence of psoriasis among children over the last 50 years [4-6].

The prevalence of psoriasis varies greatly in children depending on the country and population. In the UK, about $0.55 \%$ of children aged 0-9 and 1.37\% aged 10-19 have psoriasis [7]. The prevalence among Germans aged 0-9 is $0.18 \%$; aged $10-19$ $0.83 \%$ [8] and in the Dutch population aged $0-10-0.4 \%$ at the age of $11-19$ years-1.0\% [9,10]. Unlike in Europe, pediatric psoriasis was not normally observed in epidemiological studies of pediatric dermatoses conducted in Asia [11-13]. This global geographical variation seems to reflect the fact that psoriasis tends to be a complex disease caused by environmental factors in genetically predisposed subjects [14-15].

In children with psoriatic manifestations, comparable to those observed in adults, the lesions differ in location and morphology, while their clinical symptoms differ from those typical for adults. In childhood typical psoriatic patches are thinner and smaller, and more often localized on the face and in the skinfolds. Such lesions are characterized by maceration. Despite these features, psoriatic papules and patches can be located in any skin area and usually symmetrically $[16,17]$. Rashes in the diaper area that do not respond on the conventional therapy of diaper dermatitis tend to appear frequently in young children. Such a rash is characterized by
Quick Response Code:

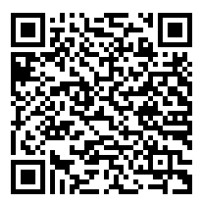

Address for correspondence: Elvina Murzina, Department of Dermatovenereology, Shupyk National Medical Academy of Postgraduate Education, Ukraine

Received: February 13, 2020 Published: February 27, 2020

How to cite this article: Elvina M. Pediatric Psoriasis: Clinical Features and Course. 2020 2(1) OAJBS.ID.000147. DOI: 10.38125/OAJBS.000147 
sharply demarcated infiltrated erythematous patches in the diaper area involving inguinal skinfolds. Lesions are often macerated and capable of spreading to surrounding areas [18]. Up to $75 \%$ of all cases in elder children manifest as patches $[19,20]$. It is the prevailing psoriasis type in children and adults and characterized by sharply demarcated infiltrated erythematous papules or patches accompanied by a silver-white skin exfoliation. Lesions vary in size and appear mainly on the scalp, face and elbows as well as knees. Lesions of the scalp are the most common among the affected areas and often are the initial manifestation of psoriasis in children $[21,22]$.

\section{RESEARCH OBJECTIVES}

These define clinical features and epidemiology of psoriasis in children.

\section{MATERIALS AND METHODS}

We examined 260 children with psoriasis aged 4-17 who underwent inpatient treatment in Kyiv Municipal DermatologySTI Clinic in 2017-2019. Children were divided into groups depending on the biological age grouping: group 1-early childhood or 4-7-year-olds-37 children (14.23\%), group 2-middle childhood, 75 children (28.85\%)- 8-11-year-old girls, 8-12-year-old boys, group 3-adolescents-119 children (45.76\%) - 12-15-year-old girls, 13-16-year-old boys and group 4-17-year-old boys and 16-17-yearold girls, 29 people overall (11.15\%).

\section{RESULTS}

The mean age of the children with psoriasis who were examined and underwent inpatient treatment in Kyiv Municipal DermatologySTI Clinic in 2017-2019 was an $11.96 \pm 0.22$ year in parallel with the disease duration ranging between 1 month and 15 years. The girls and boys were divided equally. The group comprised of 16-17-yearolds included the greatest number of boys-55.17\%, the greatest number of girls was in 4-7-year-old group-72.97\%. The average duration of the last exacerbation or manifestations was $11.45 \pm 1.05$ months.

Examining the children with psoriasis we defined that typically exacerbation develops in August, then the exacerbation curve will rise and peak in October-November, and exacerbation rates (Figure 1) stay high over the period of the last winter and spring months.

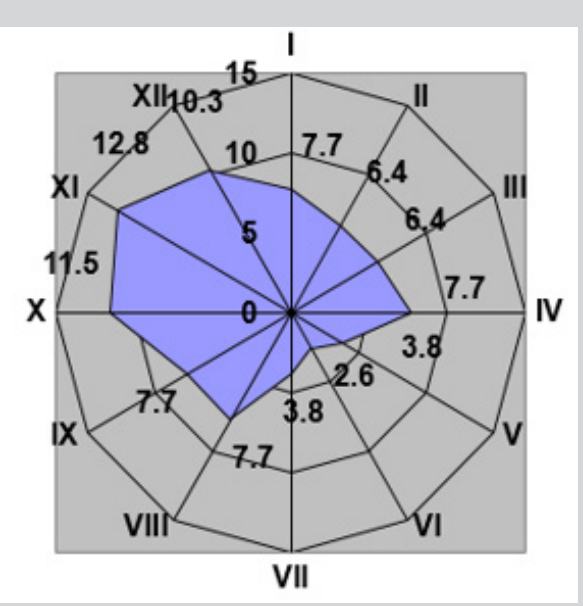

Figure 1: Exacerbation onset depending on the month of the year (as a percentage).

The mean age of the disease onset in children examined was 9-10 years. The mean age of the disease onset in group 4 was 13.00 \pm 0.84 years, group $3-11,34 \pm 0.30$ years, group 2 -8.35 \pm 0.22 years and group 1-5.019 \pm 0.21 years.

Only $74(28.46 \%)$ patients or their parents were able to identify or recall the cause of the disease onset. Among these causes: $56(75.68 \%)$ patients mentioned severe or chronic stress that preceded the disease onset, $9(12.16 \%)$ patients mentioned the initial manifestations of psoriasis after the infectious disease, extra 9 patients link the onset with the failure to stick to a diet.

Psoriasis is more commonly progresses as an extensive process, we observed in 193 children. Nail pitting, deformity or thinning of the nail plates were observed in one quarter of children (26.54\%). The localized process accompanied only by affecting the scalp (scalp psoriasis, SP) was found in 39 (15.00\%) children, palms and feet (palmo-plantar psoriasis, PPP) were affected in 8 children with psoriasis. In the context of age groups we were tracing the aging-related decrease in the number of children with the extensive process, and if $30(81.08 \%)$ children were affected with the extensive process in group 1, only $20(68.96 \%)$ patients, of 29 affected, had the extensive process in group 4.

Although it is considered that the most common type is guttate psoriasis (GP), in our study plaque psoriasis (PP) prevailed, in 153 children $(58.85 \%)$. Guttate, as well as scalp psoriasis, occurred almost with equal frequency or $14.23 \%$ and $15.00 \%$ respectively. However, in young children (4-7 years) guttate psoriasis occurred in every fourth child. Inverse psoriasis (IP) was diagnosed in 21 of 260 children. Group 3 included the greatest number of children with inverse psoriasis, but almost $13.5 \%$ of cases of this type occurred in the group "middle childhood". Also, exudative psoriasis (EP) was observed in 2 children (Figure 2).

Psoriasis was first-ever determined in 84 (32.31\%) children. The study revealed that although scalp lesions are considered as typical initial manifestations of psoriasis in children, in our study plaque psoriasis prevailed, in $43(51.19 \%)$ children. Psoriasis set in as guttate psoriasis in $21(25.00 \%)$ children. Scalp lesions as manifestations of psoriasis and inverse psoriasis were determined in $9(10.71 \%)$ and $10(11.90 \%)$ children respectively. Also, palmar and plantar lesions were diagnosed in one child as manifestations of psoriasis. It is worth mentioning that by considering the elder age group, the number of children with psoriasis as preliminary diagnosis significantly reduces. If in group 1 the diagnosis was firstever determined in $51.35 \%$ of children, then in group 4 psoriasis was determined as preliminary diagnosis only in 3 children, which equals $10.34 \%$ of cases. 


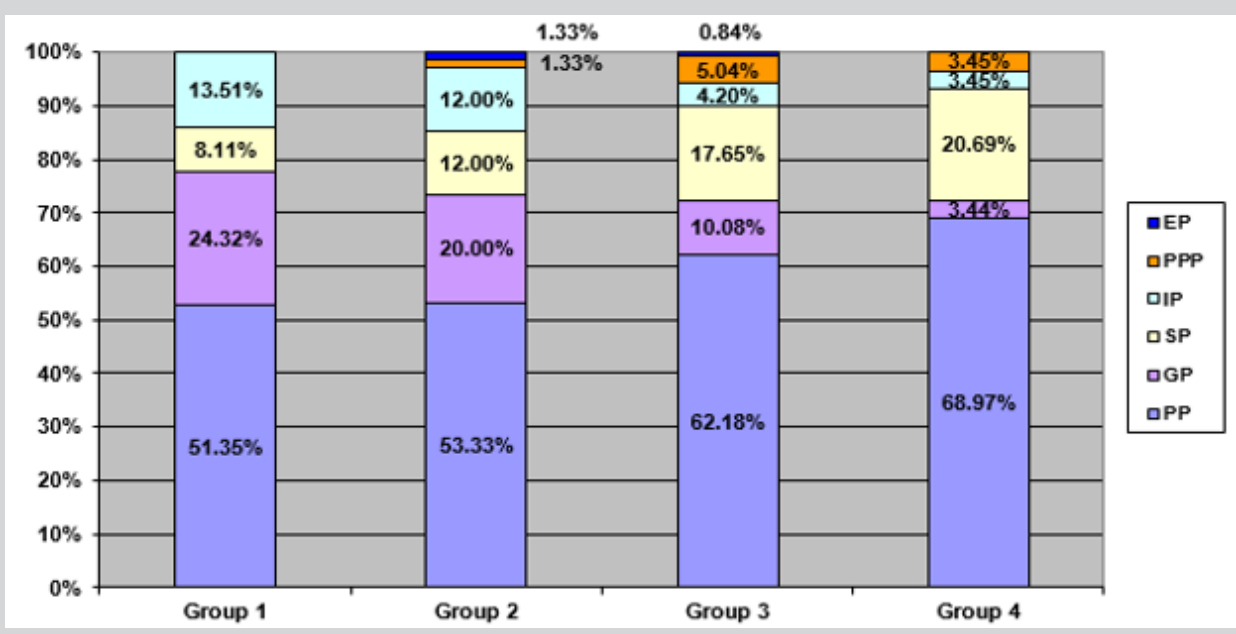

Figure 2: Psoriasis clinical types in different age groups.

\section{CONCLUSION}

The analysis revealed that psoriasis is fairly widespread dermatosis, among children and adolescents, affecting boys and girls in equal measure. The disease can develop at any age and have durable course. The greatest number of children with durable and extensive course comprises children aged 8-15/16. Among the triggers that provoke psoriasis in children acute or chronic stresses head the list. Among the manifestations of psoriasis, the extensive process prevails. Plaque psoriasis is the most common, the number of children with this type increases with their aging: from $51.35 \%$ of children in group 1 to $68.97 \%$ of children in group 4 . The ageassociated gradual increase in the number of children with scalp lesions is also observed: scalp psoriasis occurs only in $8.11 \%$ of children in group 1, 20.69\% - group 4. Consideration should be given to the significant incidence, in children of early and middle childhood, of long-lasting inverse psoriasis, resulting from the localization in the skinfolds and genitals, susceptible to maceration and rapid exacerbation following the treatment.

\section{REFERENCES}

1. Ashakov MS (2013) Vestnik molodogo uchenogo. Journal of Young Scientist 3(1): 49-51

2. Habif TP (2016) Psoriasis and other papulosquamous diseases. Clin Dermatol 263-328.

3. Man MQ (2015) Could psoriasis be preventable? Dermatologica Sinica 33(4): 243-244.

4. Kumar B, Jain R, Sandhu K, Kaur I, Handa S (2004) Epidemiology of childhood psoriasis: a study of 419 patients from northern India. Int J Dermatol 43(9): 654-658.

5. Raychaudhuri SP, Gross J (2000) A comparative study of pediatric onset psoriasis with adult onset psoriasis. Pediatr Dermatol 17(3): 174-178.

6. Sommer R, Mrowietz U, Radtke MA, Schafer I, Von Kiedrowski R, et al. (2018) What is psoriasis? -Perception and assessment of psoriasis among the German population. J Dtsch Dermatol Ges 16(6): 703-710.

7. Gelfand JM, Weinstein R, Porter SB, Neimann AL, Berlin JA, et al. (2005) Prevalence and treatment of psoriasis in the United Kingdom: a population-based study. Arch Dermatol 141(12): 1537-1541.

8. Augustin M, Glaeske G, Radtke MA, Christophers E, Reich K, et al. (2010)
Epidemiology and comorbidity of psoriasis in children. Br J Dermat 162(3): 633-636.

9. Matusiewicz D, Koerber A, Schadendorf D, Wasem J, Neumann A (2014) Childhood psoriasis-an analysis of German health insurance data. Pediatr Dermatol 31(1): 8-13.

10. Seyhan M, Coskun BK, Saglam H, Ozcan H, Karincaoglu Y (2006) Psoriasis in childhood and adolescence: evaluation of demographic and clinical features. Pediatr Int 48(6): 525-530.

11. Chen GY, Cheng YW, Wang CY, Hsu TJ, Hsu MM, et al. (2008) Prevalence of skin diseases among schoolchildren in Magong, Penghu, Taiwan: a community-based clinical survey. J Formos Med Assoc 107(1): 21-29.

12. Chiam LY, de Jager ME, Giam YC, de Jong EM, van de Kerkhof PC, et al. (2011) Juvenile psoriasis in European and Asian children: similarities and differences. Br J Dermatol 164(5): 1101-1103.

13. Yang YC, Cheng YW, Lai CS, Chen W (2007) Prevalence of childhood acne, ephelides, warts, atopic dermatitis, psoriasis, alopecia areata and keloid in Kaohsiung County, Taiwan: a community-based clinical survey. J Eur Acad Dermatol Venereol: JEADV 21(5): 643-649.

14. De Jager ME, Van de Kerkhof PC, De Jong EM, Seyger MM (2009) Epidemiology and prescribed treatments in childhood psoriasis: a survey among medical professionals. J Dermatol Treat 20(5): 254-258.

15. Howard R, Tsuchiya A (1998) Adult skin disease in the pediatric patient. Dermatol Clin 16(3): 593-608.

16. Christophers E (2001) Psoriasis-epidemiology and clinical spectrum. Clin Exp Dermatol 26(4): 314-320.

17. Tollefson MM (2014) Diagnosis and management of psoriasis in children. Pediatr Clin North Am 61(2): 261-277.

18. Shah KN (2013) Diagnosis and treatment of pediatric psoriasis: current and future. Am J Clin Dermatol14(3): 195-213.

19. Benoit S, Hamm H (2007) Childhood psoriasis. Clin Dermatol 25(6): 555-562.

20. Ray-Jones H, Eyre S, Barton A, Warren RB (2016) One SNP at a time: moving beyond GWAS in psoriasis. J Invest Dermatol 136: 567-573.

21. Silverberg NB (2009) Pediatric psoriasis: an update. Ther Clin Risk Manag 5: 849-856.

22. Sugiura K (2014) The genetic background of generalized pustular psoriasis: IL36RN mutations and CARD14 gain-of-function variants. J Dermatol Sci 74: 187-192. 